\title{
Una recreación narrativa del Quijote de mediados del siglo XX: Don Quijote en las Améscoas, de Martín Larráyoz Zarranz
}

\author{
Carlos Mata Induráin*
}

A Joaquín Ansorena y Ángel de Miguel, buenos amigos, «sabidores» de algunos secretos que encierra este trabajo

En el presente artículo $^{1}$ me propongo estudiar una recreación narrativa del Quijote de mediados del siglo XX que traslada al hidalgo manchego y a su escudero Sancho Panza a tierras navarras y describe sus andanzas, durante un solo día, en una comarca de Tierra Estella. Me refiero a la novela Don Quijote en las Améscoas, de Martín Larráyoz Zarranz, publicada en 1954 en una revista diocesana pamplonesa (con una circulación muy limitada, por tanto) y recuperada luego en forma de libro a la altura de 1993 (pero también en una editorial de ámbito regional, con muy escasa difusión más allá de las mugas forales). La obra, no exenta de humor, resulta interesante - lo adelanto yano tanto por los primores de su calidad literaria, sino sobre todo por constituir un eslabón más en la larga y fecunda cadena de recreaciones del inmortal personaje cervantino y sus aventuras, una prueba más de su enorme vigencia como mito universal, de su potencialidad para ser recuperado y revivificado en multitud de obras literarias y artísticas.

* GRISO-Universidad de Navarra.

1. Este trabajo forma parte del proyecto «Recreaciones quijotescas y cervantinas (RQC)», que dirijo en la actualidad en el marco de las investigaciones del Grupo de Investigación Siglo de Oro (GRISO) de la Universidad de Navarra. La novela de Martín Larráyoz Zarranz es una de las numerosísimas recreaciones del Quijote en la narrativa, tema sobre el que existen abundantes estudios; me limito a remitir ahora a la monografía de Santiago Alfonso López Navia, Inspiración y pretexto. Estudios sobre las recreaciones del "Quijote», Madrid-Frankfurt, Iberoamericana-Vervuert, 2005, donde el lector interesado encontrará abundantes comentarios y una rica bibliografía. 
Respecto al autor de Don Quijote en las Améscoas, Martín Larráyoz Zarranz, basta para mi propósito de ahora recordar algunos datos biográficos esenciales. En este sentido, la nota biográfica redactada por Juan María Lecea Yábar que aparece al final de la edición de Don Quijote en las Améscoas (Pamplona, Medialuna Ediciones, 1993) recoge una información bastante completa, así que me limitaré aquí a reproducirla:

Nació (1918) y murió (1991) en Pamplona. Licenciado en Teología por la Universidad Pontificia de Salamanca, y en Filosofía y Letras por la Universidad Central de Madrid. Ordenado sacerdote en 1943.

$\mathrm{Su}$ actividad intelectual se encauzó principalmente por las vertientes de la historia y del arte, y tuvo un centro de mira casi obsesivo: Navarra. A su historia aportó, sobre todo, el descubrimiento y registro de los ricos fondos documentales de los Archivos de París; sus catalogaciones se entregaron al Archivo de Navarra. En 1977 publicó, en colaboración con su hermana Josefina, el primer tomo de la Historia de la cultura y del arte de Pamplona, que no pudo concluir. Contribuyó decisivamente a la creación del Museo Diocesano de Pamplona y a la restauración artística de muchas iglesias navarras. Trabajó como alto funcionario en la Institución Príncipe de Viana desde 1978 a 1984.

Educador y maestro en el Seminario, donde fue Vicerrector, y Profesor en la Escuela de Peritos Agrícolas, despertó y encauzó no pocas vocaciones científicas.

Hombre de amplios saberes, humanista integral, trazó para sus alumnos del Seminario, hace ya 40 años, un mapa geológico de Navarra. Explicaba la evolución de las especies o daba clases de Griego o de Literatura. Alguna pintura mural suya queda aún en aquellas paredes.

Como teólogo, se dedicó principalmente al estudio de la vocación sacerdotal. La vocación sacerdotal según la doctrina del Beato Juan de Ávila y La vocación misionera según las cartas de San Francisco Javier son dos obras publicadas en 1949. Fue párroco de Sarasa desde 1972 hasta 1986. Capellán durante muchos años de la Asociación de Belenistas y de las «Colonias» veraniegas de la Caja de Ahorros de Navarra en Zudaire.

Trabajador incansable, estuvo entregado siempre al servicio de los demás, desde los días de la guerra civil, en que, aún seminarista, fue jefe de enfermeros en el hospital de guerra «Alfonso Carlos» de Pamplona, hasta que una grave y larga enfermedad puso fin a sus numerosas actividades (pp. 7-8).

\section{ESTRUCTURA Y CONTENIDO DE DON QUIJOTE EN LAS AMÉSCOAS}

Fue en enero de 1954, y en la revista Pasce. Boletín Oficial Eclesiástico de la Diócesis de Pamplona, cuando comenzó a aparecer una serie de escritos de 
Martín Larráyoz Zarranz titulada «Rincones perdidos del Quijote» ${ }^{2}$, que venía a ser una continuación por tierras navarras de las andanzas y aventuras del ingenioso hidalgo y su fiel y bonachón escudero. Unas décadas después, tras la muerte del autor ocurrida en 1991, Víctor Manuel Arbeloa tuvo la iniciativa de coleccionar en forma de libro (Pamplona, Medialuna Ediciones, 1993³), aquellos capítulos, anteponiéndoles un prólogo que arrojaba luz, entre guiños personales, sobre la génesis del texto y comentaba algunas características (argumento, valoración literaria...) de este Don Quijote en las Améscoas, cuya publicación arrancaba en aquel lejano enero de 1954:

Aquellos sesudos y graves editores tuvieron a bien advertir en la entradilla que presumían como inéditos los susodichos capítulos, hallados en las últimas páginas de un viejo libro que dormía arrinconado en el desván de la abadía de Izacondo, soportando pacientemente el polvo de los siglos.

Los discípulos de aquel afamado y todavía joven abad no dudamos un instante que aquella nueva leyenda, fresca como una primavera, fecunda de invención, robusta de estilo, rica de conceptos y abundante de erudición y doctrina, fuera obra, y obra madura, de nuestro querido y ahora llorado preceptor, don Martín Larráyoz y Zarranz, y no de algún ignorado y extraño Cide Hamete Benengeli. [...]

No pocas veces habíamosle oído quejarse muy a lo vivo de que don Quijote de la Mancha y Sancho Panza no hubieran entrado en el reino de Navarra cuando atravesaron la provincia de Zaragoza, camino de Barcelona.

Púsose, pues, nuestro autor manos a la obra, con el intento de hacer resucitar literariamente - que es como decir poderosamente- a los dos excelsos personajes de nuestras Letras y hacerlos entrar en vereda, es decir, por las verdes veredas navarras. $\mathrm{Y}$ es que el erudito abad, historiador de peso, abrigaba la convicción de que al caballero hazañoso, y no tanto a su fiel escudero, le roía las entrañas la rencilla de haber muerto sin pisar este esclarecido y glorioso territorio foral (pp. 9-10).

Remito, en fin, a ese prólogo de Arbeloa para más detalles acerca de la génesis y las circunstancias de aparición del libro. El texto de la novela se completaba entonces con una nota biográfica anexa - la que he reproducido más arriba-, que no va firmada, aunque Arbeloa explica en su prólogo que

2. Mencionaré, a título de curiosidad, que el hermano del autor, Javier Larráyoz Zarranz, también sacerdote y también historiador, cuenta en su haber con otra obra de reminiscencias quijotescas, al menos en su título: «El Quijote de Navarra. Vida y aventuras del brigadier de los ejércitos carlistas don Mariano Larumbe», trabajo publicado en Príncipe de Viana, n. ${ }^{\text {os }} 148-149$, 1977, pp. 605-627 y 150-151, 1978, pp. 203-280.

3. Esta edición al cuidado de Víctor Manuel Arbeloa, bienintencionada y útil porque hizo más accesible el texto de la novela, está sin embargo plagada de erratas, errores de transcripción, descuidos y hasta faltas de ortografía, además de presentar una puntuación arbitraria en muchos pasajes. Citaré por ella, pero corrigiendo y enmendando todo lo necesario, sin indicarlo a cada paso. Las citas del Quijote de Cervantes (indico solamente parte y capítulo) corresponden a la edición del Instituto Cervantes dirigida por Francisco Rico, Barcelona, Crítica, 1998, 2 vols. 
fue redactada por el bachiller Johannes de Lecea, alusión casi transparente a Juan María Lecea ${ }^{4}$.

Fue, en efecto, a la muerte de Larráyoz Zarranz cuando Arbeloa agavilló y dio a las prensas los capítulos aparecidos en Pasce. Aquella era una revista que circulaba casi exclusivamente entre los sacerdotes de la diócesis de Pamplona, y sin duda que el texto de Larráyoz Zarranz merecía mayor difusión. La novela, tal como se publicó en 1993, se divide externamente en dieciséis capítulos, y está sin concluir: de hecho, el último capítulo es mucho más breve que los demás y el hilo argumental parece quedar interrumpido justo en el momento en que don Quijote y Sancho se disponen a entrar en la ciudad de Estella. Juan María Lecea me ha dado noticia de la existencia de, al menos, otro capítulo, publicado suelto en la revista de la Asociación de Belenistas de Pamplona en el año 1956, el cual recoge la llegada de don Quijote a Pamplona y su encuentro con la hermosa imagen de la Virgen, patrona de la ciudad, entre otras aventuras, capítulo este que viene a completar así la historia narrativa de las andanzas del personaje cervantino por tierras navarras.

La acción narrada en Don Quijote en las Améscoas ocupa un solo día de un año indeterminado: en efecto, no hay indicaciones cronológicas concretas, si bien por algunas alusiones y pistas que proporciona el texto podríamos pensar que se localiza hacia finales del siglo XIX o comienzos del $\mathrm{XX}^{6}$ : por la mañana tiene lugar la conversación de don Quijote y Sancho con el carbonero Saturnino; luego el encuentro con los sacerdotes navarros cabe la fuente de Odoliturri; y a última hora de la tarde, su asistencia a un funeral de segunda (en esa misa, por cierto, Sancho se queda dormido y lanza unos furibundos y espantables ronquidos) y la ulterior y accidentada cena con los clérigos. Se da, por tanto, una concentración espacial (la zona geográfica de las Améscoas ${ }^{7}$ ) y temporal (menos de veinticuatro horas), lo que aumenta la intensidad de los acontecimientos narrados.

4. En ese prólogo se alude también a un tal Johannes de Olio, nombre que remite a Juan Ollo, profesor de Teología Moral en el Seminario Diocesano de Pamplona y deán del Cabildo catedralicio cuando era Arzobispo de Pamplona Mons. Enrique Delgado Gómez.

5. Agradezco a Juan María Lecea Yábar sus valiosas informaciones relativas a la génesis de la novela. También quiero dar las gracias a Pablo Larraz por los datos que amablemente me ha proporcionado acerca del trabajo desempeñado por Lárrayoz Zarranz en el Hospital «Alfonso Carlos» de Pamplona. Esos datos no han quedado incorporados a este trabajo, pero me han servido, sin duda, para completar la semblanza, el retrato humano, del autor de Don Quijote en las Améscoas. El lector interesado puede consultar el trabajo de Pablo Larraz, Entre el frente y la retaguardia. La sanidad en la guerra civil: el Hospital «Alfonso Carlos», Pamplona, 1936-1939, Madrid, Actas, 2004.

6. Aunque tampoco faltan otras alusiones contemporáneas al momento de redacción de la novela, es decir, mediados del siglo XX.

7. La comarca de Améscoa o las Améscoas (cuyo nombre deriva del vascuence ametz «roble») se localiza en el extremo noroccidental de la merindad de Estella (Navarra), próximo a la divisoria con Álava. Ocupa un largo valle entre las sierras de Urbasa y de Lóquiz, más la franja meridional de Urbasa, más la parte septentrional de Lóquiz. Está formada por once lugares: tres de ellos (Aranarache, Eulate y Larraona) tienen carácter de municipios independientes y forman la denominada Améscoa Alta; a su vez, la Améscoa Baja incluye los ocho pueblos restantes (Artaza, Baquedano, Baríndano, Ecala, Gollano, San Martín, Urra y Zudaire), que tienen carácter de concejo y constituyen un solo ayuntamiento. 
Es en el capítulo II de la novela donde se explica que Dios ha permitido la resurrección de don Quijote para que pueda ver finalmente cumplido su deseo de pisar tierra navarra. Cuando el carbonero navarro ${ }^{8}$ les pregunte a don Quijote y Sancho cómo es posible - si es por brujería o cómo- que estén allí delante de sus ojos, en carne y hueso, aquellos tan famosos personajes conocidos por las enseñanzas de la escuela, responde el escudero:

\begin{abstract}
-Por la gracia de Dios, que no por arte de brujería ni encantamientos, somos don Quijote y Sancho Panza — respondió este-. Obra suya es el habernos vuelto a la vida a mi amo y a mí, a su Rocinante y al rucio de mis entrañas, que sin él, bien lo sabía Dios, ni yo acertara a vivir, ni Él a resucitarme. [...] El cual [Dios], por quitar a mi amo la rencilla, que tiempo ha le roía las entrañas, de haber muerto sin pisar tierra de aqueste reino de Navarra, tornado nos ha a este mundo pecador; a mi amo, según veo, tan loco como antaño; a mí, tan hombre de paz y seso, aunque mal está sea yo quien lo diga; a su rocín, tan largo como centeno soriano y más flaco y doliente que el galgo de Lucas, que tenía que apoyarse en la pared para ladrar; y a mi rucio, tan enamorador como docena y media de princesas Briolanjas (p. 29).
\end{abstract}

En cuanto a los distintos componentes que entran en la novela (narración, diálogos y descripción), hay que decir que el diálogo predomina notablemente sobre la narración: suceden algunas aventuras, ciertamente, que son contadas, pero la acción de la novela es más reducida que la parte dialogada. Es más, a veces la acción es meramente verbal. Así, en el capítulo I, el diálogo mantenido entre don Quijote y Sancho se ve turbado tan solo por la presencia de una molesta mosca de macho que incomoda a Rocinante; luego, tras el encuentro con el carbonero, ambos sufren una pedrea por parte de unos mocetes... y muy poco más es lo que encontramos de acción en la novela, si descontamos la accidentada «misa y mesa» con los canónigos navarros. Hay, en efecto, un predominio muy claro del diálogo. Especialmente interesante, desde el punto de vista lingüístico, son los capítulos II y III, en los que se reproduce el habla popular del carbonero, que refleja el habla propia de la zona (vulgarismos coloquiales y navarrismos específicos de la zona de Tierra Estella). El paisaje - tercer elemento compositivo en cualquier narraciónqueda reflejado puntualmente a lo largo de la obra, y de forma más intensa en los primeros capítulos.

Siguiendo con ese predominio de «lo hablado» frente a «lo actuado», debemos consignar que en el capítulo V don Quijote reprende a Sancho por su continuo y fatigoso hablar, igual que sucede en el Quijote cervantino en distintas ocasiones (recordemos que, enfadado por su verbosidad desatada, don Quijote prohibirá hablar a su escudero, aunque pronto tendrá que levan-

8. La sorpresa que causa al carbonero la visión de don Quijote con su armadura y su lanza se expresa con estas palabras: «-Y ¿pa qué va forrau de tanta hojalata [...], que paece un hombre en conserva? Y tamién, ¿qué demoño pinta con esa charrancha o estaca en la mano, igual que el Longinos de la procesión de Viernes Santo?» (p. 28). 
tar ese entredicho, ya que de otra forma la novela resultaría imposible: la estructura dialogada que se da entre la pareja de protagonistas es esencial en la construcción del Quijote). Carencia absoluta de acción hay también en el capítulo XV, que resulta demasiado aburrido, pues se limita a ofrecer un catálogo de próceres navarros, todos ellos relacionados con la «Caja de Comptos de Navarra $»^{9}$, al tiempo que se alude a las famosas colonias educativas para niños que esta institución financiera organizaba en el pueblo de Zudaire (localizado, precisamente, en las Améscoas). El autor aprovecha la circunstancia de la visita de don Quijote a una de las reuniones de tales célebres prohombres navarros para trazar la semblanza de varios de ellos, mencionar algunas de las actuaciones que impulsaron y rendirles tributo de gratitud; sin embargo, toda esta parte es algo que tiene muy poco (o nada) que ver con el hilo principal del relato, con la historia central de don Quijote de la Mancha.

\section{Personajes. Don Quijote, adalid de Navarra}

Evidentemente, no cabe establecer un parangón ni de calidad, ni en cuanto a la profundidad psicológica, con los inmortales don Quijote y Sancho Panza de Cervantes. Pretender tal cosa sería un verdadero desatino. El autor ha conservado, simplemente, los rasgos esenciales del carácter de cada uno: por un lado, la locura y la idealidad de don Quijote (su fantasía caballeresca que le lleva a deformar la realidad para ajustarla a su quimérico mundo soñado), su fabla arcaizante, su misión como caballero andante de desfacer entuertos y socorrer a doncellas y menesterosos, su amor por Dulcinea...; y, por otra parte, en lo que toca a Sancho Panza, su simplicidad y su pragmatismo (cobardía, afición a la comida y la bebida, gusto por los refranes...). El carácter esquemáticamente contrapuesto de ambos personajes queda ya apuntado por Larráyoz Zarranz nada más comenzar el relato, en las primeras líneas, que marcan claramente la diferencia entre ambos; don Quijote mira el horizonte, mientras Sancho Panza tiene fijos sus ojos en unas empanadas:

\footnotetext{
Un buen trecho llevaban caminando en silencio don Quijote de la Mancha y Sancho, su escudero, fijos aquel los ojos en el horizonte, que se les trocaba en montañoso, y fijos los suyos Sancho en un par de empanadas, bien ungidas de aceite y alegradas con ajo, obsequio del último mesón que dejaran atrás en la Rioja alavesa, cuando don Quijote, parado que hubo el paso indeciso de Rocinante, dijo... (p. 15).
}

9. Es decir, la Caja de Ahorros de Navarra, modificado levemente su nombre con el empleo del arcaísmo Comptos. Para la historia de esta institución remito a la entrada «Caja de Ahorros de Navarra (CAN)», recogida en la Gran Enciclopedia Navarra, Pamplona, Caja de Ahorros de Navarra, 1990, vol. III, pp. 47-52; y también a Arturo Navallas Rebolé (dir.), Navarra y la Caja en 75 años: 1921 1996, Pamplona, Caja de Ahorros de Navarra, 1996. 
La contraposición entre ambos sigue en el diálogo que se establece a continuación, y que ya anuncia el buen tono de estas partes dialogísticas, que va a mantenerse, por lo general, a lo largo de toda la novela:

-Aquella tierra que allí ves, Sancho hermano, es, si no yerran estos mis ojos pecadores, la mismísima del reino de Navarra. Deja, pues, en buen hora, se huelgue tu corazón con el mío, que, según le noto, anda ya dando brincos, como rapaz en víspera de fiesta.

- Muy de grado lo hiciera — respondió Sancho-, pero corazón no he más que uno, y este ocupado le tengo agora en un menester muy otro del que ocupa a vuesa merced, como es el de atender y dar cristiano hospedaje a estas empanadas, tocadas con este ajo tan alegrillo, que según me va entrando, me va pareciendo ser él la creatura por Dios elegida para solaz y refrigerio de este nuestro cuerpo de muerte (p. 16).

En esa estructura dual, Sancho va a atacar continuamente a los navarros y las cosas de Navarra, mientras que don Quijote saldrá siempre en su defensa, como paladín de su tierra y sus gentes:

\begin{abstract}
-No a todos es dado ver lo que ahora, aunque de lejos, tú y yo vemos; este pedazo de nuestra patria España, que sin haber nunca llegado hasta él, tiempo ha le traía yo muy dentro de mi entraña; este reino de Navarra, el primero, a mi entender, entre los reinos que forman el suelo de las Españas. Pues has de saber, Sancho, que en él se mecieron las cunas de los reyes que lo fueron luego de las demás partes de la España cristiana; que fue Navarra, y no otra tierra, la que dio Fernandos a León y Castilla, la que a Aragón dio Ramiros y la que diera Gonzalos a Sobrarbe y Ribagorza, hermanos todos ellos de los Garcías y Sanchos, que siguieron ciñendo las coronas deste viejo y noble reino (p.16).
\end{abstract}

Don Quijote sigue elogiando las antiguas glorias de la «vetusta y señorial Vasconia», con un retrato idealizado, que incluye desde el carácter bucólico de esta tierra (comparable a la «felice Arcadia») hasta la belicosidad y el indómito afán de independencia de sus moradores (los valientes guerreros vascones que pactan con Aníbal para acompañarlo en su marcha contra Roma, la secular lucha de las gentes del reino pirenaico contra los godos primero y contra los musulmanes después, la entronización de García Jiménez como primer rey de Pamplona, la célebre batalla de las Navas de Tolosa del año 1212 - cuyo 800 aniversario pronto vamos a celebrar - en la que Sancho el Fuerte rompe las cadenas de la tienda del Miramalolín, que quedan incorporadas - explicación legendaria - al escudo del reino...), etc. Sin embargo, Sancho Panza no se muestra tan de acuerdo con estas «glorias y loanzas del reino de Navarra» que hace su amo y — sugestionado por lo que con relación a Navarra le ha explicado un conocido suyo, un barbero natural de Peralvillo que participó en alguna acción de armas contra los navarros y que no guarda muy buen recuerdo de ellos_-, dedica estas palabras al viejo reino y a sus naturales: 
- Siempre túvela yo a Navarra por reinecillo de poca monta y muchas ínfulas, que no ínsulas, pues según oí a un barbero que sirvió al rey por estas partes, no tiene de mar puerto sino apenas uno. A sus gentes, téngolas yo por casta montaraz, de más mugre en el cuello que caletre en la cabeza, de muchos sacramentos y pocos mandamientos, fáciles para la reyerta y la guerra y mal avenidos con el sosiego y la paz, más dados al mosto y aficionados a la buena mesa que a las artes y a las letras, a no ser que les salieran en la sopa; y con los cuales, si son de pura cepa, parece que no cuenta aquello que dijo Dios a nuestro padre Adán: «Darete la mujer por compañera», pues hasta gustan de danzar solos y allá se andan dando zapatetas al aire, y aciertan un poco en sus requiebros y galanteos con las doncellas, que bien pudiera darles liciones cualquier mochacho encogido de nuestra tierra, los cuales, como sabe vuesa merced, madrugan en esto más de la cuenta (pp. 17-18).

Y la discusión sobre Navarra y los navarros se prolonga en lo que resta de este capítulo I, al tiempo que se mezcla con la descripción del paisaje de las Améscoas que contemplan los protagonistas. Como rasgo de estilo, se puede mencionar la fluida cadencia de la prosa de Larráyoz Zarranz, tanto en el discurso del narrador como en los diálogos mantenidos por la pareja protagonista.

Al comienzo del capítulo II, Sancho insiste sobre lo mismo, cuando comenta que «anduviera yo de mejor grado y con el corazón más en su sitio por este reino de Navarra si no hubiera navarros, ni quien dellos se acordare» (p. 24); a lo que don Quijote replica que deberían recorrer de rodillas el tramo que les falta hasta encontrarse con ellos, porque todos los navarros son héroes y descendientes de reyes:

- Cata y sosiégate que, si ahora vamos a vérnoslas con héroes, no es en son de guerra, sino en abrazo apretado de paz. Este trecho que nos resta hasta llegar a ellos debiéramos andarlo de hinojos y de rodillas, rogándoles a voces nos dieran a besar sus manos, que aquellos navarros que allí vemos hijos de héroes son y de estirpe de reyes (p. 25).

De hecho, el viejo tópico de la hidalguía universal de los navarros (desde tiempos de la Reconquista, todos se consideraban hidalgos por el mero hecho de ser navarros, cuya sangre no se mezcló con la de los invasores moros, y también en reconocimiento a los muchos servicios prestados al rey y al reino), defendido por don Quijote, se reitera varias veces a lo largo de la novela.

Algo después Sancho comenta al carbonero — no sin cierta sorna en la acumulación de superlativos ${ }^{10}$ — que su amo don Quijote es

10. El empleo humorístico del sufijo superlativo en -ísimo recuerda un célebre pasaje del Quijote en que Sancho, tras la intervención de la dueña Dolorida (que usa las formas cuitísima, Manchísima...) introduce muchos otros superlativos cómicos, aplicando también el sufijo a adjetivos, a sustantivos e incluso a un verbo: «—El Panza [...] aquí está, y el don Quijotísimo asimismo; y así podréis, dolorosísima dueñísima, decir lo que quisieridísimis, que todos estamos prestos y aparejadísimos a ser vuestros servidorísimos» (II, 38). 
admirador y alabador si los hay deste reino de Navarra, nobilísimo, antigüísimo, lealísimo y ecetra, y a quien agora se le ha metido en el caletre, y lo viene deseando con todo encarecimiento hace más de una legua, de besar de rodillas esas navarrísimas manos de vuesa merced (p. 28).

Más adelante, el esquema se reproduce nuevamente, no con relación a Navarra y los navarros en general, sino en lo tocante a la Iglesia navarra y sus clérigos en particular. Sancho no ve con buenos ojos a los sacerdotes navarros, en cuyo pensamiento - influido, recordemos, por las opiniones del barbero de Peralvillo- domina la imagen de curas trabucaires aficionados a encabezar partidas carlistas:

-El que vengan armados de bendiciones, mi amo, mejor es dejallo; que de los curas destas partes tengo oído irse suelen a su confesonario con el arcabuz o trabuco bajo sus capisayos, para salirse luego al frente de una partida de sus fieles hijos, por aquestos montes de Dios o del diablo, trayendo a mal andar a los reales ejércitos. ¡A fe que no dispararán con indulgencias! Guardarse es de cuerdos; que si vuesa merced confía y no teme, es sin duda porque todo lo de aqueste reino entrole por el ojo diestro (p. 38).

Y, una vez más, corresponde a don Quijote el papel de defender a Navarra vindicando las virtudes y la santidad de sus hombres de Iglesia. En cualquier caso, Sancho pronto tendrá ocasión de comprobar por su propia cuenta el buen talante de los clérigos navarros y, en este sentido, el abrazo que el cura don Ramón da al «Escudero de la Oronda Figura» resulta bien significativo.

\section{Intertextualidad CON EL QUiJOTE DE CERVANTES}

Un aspecto muy importante - de los más significativos a la hora de analizar esta novela de Don Quijote en las Améscoas - es la rica relación de intertextualidad que se establece con el Quijote de Cervantes. Como cabía imaginar, el texto de Larráyoz Zarranz entra en diálogo con el cervantino en numerosas ocasiones. Sin ánimo de ser exhaustivo, mencionaré los aspectos más destacados.

Hay, por ejemplo, claros ecos del Quijote en el empleo de algunas denominaciones para el caballero andante: el Caballero de la Triste Figura, el Caballero de los Leones o el Caballero de los Molinos (esta última denominación no se aplica a don Quijote en la obra de Cervantes, pero sabemos que esa aventura de los molinos transformados por su imaginación en gigantes es, sin duda, una de las más universales del Quijote); en la mención de diversos personajes: Rocinante y el rucio, Dulcinea, Teresa Panza, el bachiller Sansón Carrasco, entre otros; en la consideración del humor melancólico de don Quijote, según la teoría médica de los humores vigente en la época; en la 
recreación de escenas y episodios cervantinos: la aventura con «los gigantes aquellos manchegos», la de los yangüeses, la llegada a la venta (don Quijote imagina aquí que algún vigía navarro hará sonar la voz potente de su cuerno para anunciar su llegada, al igual que sucede en el Quijote al entrar en la venta donde será armado caballero, que él imagina castillo), el gobierno de Sancho de la ínsula Barataria, las enlutadas dueñas, Clavileño... Además, la milagrosa resurrección de don Quijote y Sancho recuerda el discurso que Cide Hamete Benengeli dirige a su pluma al final de la Segunda Parte, cuando solicita que nadie la tome para volver a la vida — vida literaria - a sus personajes «contra todos los fueros de la muerte». Los ecos los apreciamos también claramente en algunos detalles más concretos: así, el empleo continuo de refranes, puestos especialmente en boca de Sancho (véase más abajo), los denuestos de don Quijote por lo mucho que habla su escudero y, ya en el plano estrictamente textual, por medio de claras reminiscencias del tipo: «mi descanso es la pelea y mi manjar el desfacer entuertos»; «Érase, pues, que se era...»; «noches pasadas de claro en claro»; «aquella nunca vista escena»; «quien lo leyere»; «Íbase el dorado Apolo»; «que vieron los pasados siglos y verán los venideros», etc. También deberíamos recordar la influencia de Cervantes en el arte de titular los capítulos (por ejemplo, el título del capítulo XIV reza así: «En que se da razón del modo como la pacífica mesa trocose en agitada sobremesa y cómo la comedia estuvo a punto de dar en tragedia»).

A continuación repasaré de forma breve y esquemática algunas de estas cuestiones, dejando para un apartado distinto lo relativo a la lengua y el estilo (terreno en el que también apreciamos patentes ejemplos de intertextualidad con la obra cervantina).

\subsection{Autoría y fuentes}

Sabemos que la arquitectura del Quijote es muy compleja, con alternancia de distintos planos de ficción: el autor real de la novela, que es Miguel de Cervantes Saavedra (quien en el prólogo de la Primera Parte se nos presenta como padrastro, y no como padre, de don Quijote), el autor arábigo Cide Hamete Benengeli que historia las hazañas del caballero, el autor segundo, el traductor, los anales de la Mancha y otras fuentes diversas que registran los hechos del caballero, etc. El distanciamiento y el perspectivismo, que se suman a la ironía y la ambigüedad cervantinas (características destacadas también de toda su narrativa), hacen que muchas veces no sepamos a qué carta quedarnos. Pues bien, todos estos aspectos quedan apuntados en Don Quijote en las Améscoas, si bien las menciones no revisten tanta complejidad como en el modelo cervantino. En el capítulo V, titulado «En que se da cuenta del enojo de don Quijote al tener noticia de lo que sobre él dijera cierto clérigo letrado navarro en la lición de apertura de aulas de la Universidad Pampilonense, con lo cual se interrumpe la sarta de improperios contra la clerecía 
navarra que Sancho comenzara en el capítulo anterior», don Quijote parece rebelarse - un poco a la manera unamuniana, como el Augusto Pérez protagonista de Niebla - contra Cervantes por haberlo retratado como un pobre loco falto de juicio. En realidad, eso es lo que sucede con el personaje don Quijote descrito por Fernández de Avellaneda en su continuación apócrifa de 1614: ahí don Quijote, llamado el Caballero Desamorado (el don Quijote auténtico jamás renunciará a su ideal amoroso representado por Dulcinea, ni siquiera cuando se vea vencido en las playas barcelonesas por el Caballero de la Blanca Luna y con su arma apuntándole directamente a los ojos), sí es un loco de remate que termina sus días en un manicomio, la Casa del Nuncio de Toledo; en cambio, el personaje cervantino es un genial «loco cuerdo» o «cuerdo loco», un personaje entreverado de locura y discreción, un orate tan solo en lo atingente a la caballería pero con muy «lúcidos intervalos» cuando no se deja arrebatar por su monomanía ${ }^{11}$. Pero citemos ya esas palabras de don Quijote en el capítulo V de la novela de Larráyoz Zarranz:

-Así sabrán los mundos que don Quijote de la Mancha no es el que fingiera aquel Migueluelo de Cervantes, un antojadizo visionario de huero seso, que por una nadería perdía los estribos, sino un caballero, señor de sí y del mundo, cuerdo y sentado las veinticuatro horas del día (p. 46) ${ }^{12}$.

En otro orden de cosas, se alude a lo largo de la novela a fuentes diversas que han servido para la redacción de estos nuevos hechos de don Quijote, que aumentan el perspectivismo de la historia («el antedicho historiador», «Malas lenguas afirman»...); se hacen protestas de veracidad con relación a los hechos contados, al tiempo que se pondera su importancia, de forma similar a lo que ocurre en el Quijote cervantino («esta verdadera historia», «historia tan importante como esta»...); o se introducen comentarios metanarrativos a propósito de episodios o sucesos que quedan pendientes de un capítulo a otro («... habrá de guardarlo para el capítulo siguiente...», «... como en el capítulo

11. Recordemos que en II, 18 don Lorenzo, el hijo poeta de don Diego de Miranda, el Caballero del Verde Gabán, lo llama «un entreverado loco, lleno de lúcidos intervalos».

12. Pero en otro lugar de la novela sí que encontramos la mención «mi padre Cervantes». A continuación vienen unas palabras del propio don Quijote defendiéndose de cierta caracterización de su persona hecha en la lección magistral que una vez dio Johannes de Olio (alusión a Juan Ollo) en la apertura de aulas de la «Universidad Eclesiástica Pampilonense» (supongo que con esa denominación alude al Seminario Diocesano de Pamplona; pese a mis pesquisas, no he conseguido localizar ese texto de Juan Ollo, e ignoro incluso si llegó a publicarse), donde presentaba a don Quijote como «un psiconeurótico vulgarcejo, un tipo típico a catalogar en la casilla de los esquizofrénicos de Krapelin». Don Quijote no está de acuerdo, en modo alguno, con tal catalogación que lo convierte en un mero loco, y manifiesta su contrariedad y su profundo enojo de la siguiente manera: «¿Yo esquizofrénico? ¿Esquizofrénico yo? Ante todo, ¿quién es ese casuistilla de mala muerte, por muy mucetado que sea, para hurgar con su péñola en las más recónditas entretelas de mi ánima, o con palabra suya para hacer análisis de mi psiquis, como cuando trincha las entrañas de un orondo palomino? / ¿Yo esquizofrénico, Sancho? ¿Osará decirme que aquellos gigantes con quienes medí mis armas no eran tales gigantes sino unos molinos ventolineros? ¿Soy yo acaso un iluso? ¡Yo haré volver a tragar sus palabras al tal dómine, que en mengua de mi honor redundan, por más que vengan arropadas pomposamente con verbo cienzudo y con helenismos pedantoches!» (p. 46). 
siguiente y con la ayuda del Cielo se dirá...»), de los cuales hay también abundantes ejemplos en el Quijote. Baste recordar el episodio de la pelea con el escudero vizcaíno, que queda interrumpido al final del capítulo I, 8 (ambos contendientes con las espadas en alto), y que no se completa hasta el capítulo siguiente, merced al hallazgo del cartapacio con papeles arábigos que descubre el narrador-autor en el Alcaná de Toledo (hallazgo que le permite seguir contando las hazañas de don Quijote).

\subsection{Encantadores}

Encontramos algunas alusiones a los «encantadores invidiosos ${ }^{13}{ }^{13}$ (envidiosos, se entiende, de las hazañas y la fama de don Quijote) y a sus encantamientos (y, en concreto, al "gigante encantador Malambruno»). Ellos son, como en el Quijote, quienes le atormentan trastocando la realidad para robarle la honra y prez que sin duda ganaría en todas sus aventuras con la fuerza de su valiente brazo, movido siempre al impulso ideal de su Dulcinea. Así, en el capítulo II Sancho Panza ve la realidad tal cual es, un carbonero navarro, pero don Quijote se empeña en imaginar que tal personaje es un príncipe (esto es, justamente, lo que sucede en la Primera Parte del Quijote: el hidalgo manchego deforma la realidad para ajustarla a las características de su monomanía caballeresca; en cambio, en la Segunda Parte son otras personas - el cura y el barbero, Sansón Carrasco, los Duques...- las que transmutan esa realidad, que don Quijote ve ahora tal cual es, con el fin de llevarlo de vuelta a casa, o peor - en el caso concreto de los Duques - , para burlarse cruelmente de él y reírse a su costa). En efecto, al ver al carbonero, dice Sancho:

— También lo digo yo [...], pero cátese bien mi amo antes de lo que hace, que aquellos no parecen príncipes de sangre, ni tan siquiera marqueses, ni condeses. Al menos, aquel que yo mejor veo, por la negrura de su rostro y manos, más parece demonio de pura raza escapado de alguna zahúrda de Satanás que infante criado en los palacios con leche azaharada y lengüítas de pavo real. A lo más, y perdonándole mucha mugre, daríale yo cédula de carbonero, que tales y tan negros suelen andar por mi tierra los que trabajan en aquestas labores (p. 25).

Y más tarde, cuando le explica que don Quijote quiere acercarse a besar sus manos, añade que lo hará «estén ellas como estuviéreden, ambaradas si sois príncipe, u hollinadas si carbonero, según se les antoja a estos mis ojos, aunque, a lo que creo, ahora me mienten como bellacos» (p. 28).

Algo similar sucede en el capítulo IV, cuando los clérigos que se presentan ante su vista (y que Sancho, por supuesto, identifica claramente como tales)

13. Y el adjetivo follones «malandrines, desalmados», que suele aparecer ligado en el Quijote a los encantadores y gigantes, lo encontramos aquí en el sintagma «cleros tan follones». 
se le representan a don Quijote, en su fantástica imaginación, como viudas enlutadas:

- Con la Iglesia tornamos a topar, mi señor don Quijote, que aquellas cuentas negras que lueñe veíamos, no en otra cosa se han trocado sino en otros tantos curas, enteros y verdaderos, tanto o más que los de nuestra tierra.

- ¿Y cómo lo conociste, Sancho?

— ¿En qué voy a conocer que de día estamos? — respondió Sancho-. Tan simple es, pues vienen como entalegados de pies a cabeza y más negros que la noche. Quijote.

— ¿Y no pudieran ser una caterva de viudas enlutadas? — replicó don

- Rasúreme en seco si aquellos no son tan clérigos como el que más pudiere serlo en Roma, que antes confundiera yo una gallina con un alguacil de a caballo, si los hubiere, que a una dueña plañidera con un cura navarro. (p. 38).

— ¿Curas y navarros? Buena nueva me das, Sancho — dijo don Quijote

A su vez, llama la atención que estos simpáticos curas navarros no crean de entrada que se encuentren ante ellos los verdaderos don Quijote y Sancho, como si dijéramos «en carne y hueso», sino que piensan que se trata de dos gangarilleros, es decir, dos actores de teatro que representan el papel de las inmortales creaciones cervantinas (y tal vez no estaría de más relacionar este aspecto con el motivo del juego y la representación, tan presente en todo el Quijote, y muy especialmente en la Segunda Parte).

\subsection{Lo caballeresco}

El tema caballeresco se hace presente en Don Quijote en las Améscoas a través de la mención de ciertos nombres como Amadises, Palmerines y Cirongilios; se alude además a la famosa historia del Caballero y el Cisne, o se habla de ciertas princesas Briolanjas, de la princesa Magalona... Pero más interesantes que estas alusiones sueltas son los pasajes en los que Larráyoz Zarranz inventa algunas nuevas aventuras pseudocaballerescas, por ejemplo la historia de la «mustia infanta Isomberta», en el episodio de la alacena de la casa rectoral de San Martín de Améscoa. Ese nombre de Isomberta pertenece a la tradición caballeresca, y su historia, recogida en la Gran conquista de Ultramar, preludia la del Caballero del Cisne. Sin embargo, hasta donde se me alcanza, no lo encuentro documentado en el Quijote ${ }^{14}$, donde sí son frecuentes las referencias

14. En efecto, Isomberta no figura en Juan Bautista de Avalle-Arce, Enciclopedia cervantina, 2. ${ }^{\mathrm{a}}$ ed., Guanajuato (México), Universidad de Guanajuato, 1997; ni tampoco en Carlos Alvar (dir.), Alfredo Alvar Ezquerra y Florencio Sevilla Arroyo (coords.), Gran enciclopedia cervantina, vol. VII, Ínsula Firme-luterano, Madrid, Castalia-Centro de Estudios Cervantinos, 2008. 
a aventuras caballerescas protagonizadas por menesterosas damas ${ }^{15}$. Parece, pues, invención de Larráyoz Zarranz esta famosa aventura de la alacena narrada en el capítulo XII: «De la misteriosa alacena que descubrió don Quijote en la sacristía de San Martín de Améscoa, con otros regocijantes sucesos dignos de referirse». Al verla, don Quijote exclama:

- iAlégrese la mustia infanta Isomberta, que ya di con la alacena de las seis llaves, en donde se esconde sin duda el talismán que trocará en claro gozo su negro dolor! (p. 94).

\section{Y poco después explica las razones de su contento:}

- ¿Quién ignora que la fiel infanta Isomberta vio bendecidos sus amores hacia el temerario conde Eustasio con el alumbramiento de siete angelicales mellizos? ¿Quién desconoce la larga envidia y retuerta trapacería de su artera madrastra - madrastra, el nombre le basta - que envió recado al buen conde, anunciándole que su mujer había dado a luz, ¡oh, infamia!, siete cachorrillos podencos? ¿Quién no sabe como los siete infantes, acurrucados en el hueco de un añoso roble en el fondo de un bosque, fueron amamantados por una cierva y educados ocultamente por un ermitaño? ¿Quién no conoce como al dar con ellos los esbirros de la madrastra para matallos, tornáronse en otros tantos cisnes, que huyeron raudos por los aires graznando cua, cua? ¿Quién no sintió henchido su pecho de justo gozo al ver satisfecha la justicia con el emparedamiento de la pérfida madrastra, que mal poso haya su ánima? ¿Y quién de voacedes, clérigos navarros venerables, no mezcló luego sus lágrimas con las de la egregia y cuitada Isomberta, cuando aquella sufrió tamaño desencanto, como lo fue el de ver desencantados a todos sus hijos menos a uno, al cual solo no le fue dado tornar a su prístino y natural ser, y hubo de continuar con la figura de cisne, por razones luengas de explicar y sobradamente de todas vuesas reverendas mercedes conocidas? ¿Y quién, en fin, no está sabidor de que el contrahechizo para sacallo de su encantamiento, ora fuese un talismán, ora un amuleto, ora unas hierbas, quizás un ungüento, tal vez un mejunje, hállase puesto a buen recaudo en un lugar escondido y apartado del siglo, como lo es aqueste de la Améscoa, en una férrea alacena, como lo es también aquesta, y cerrado con seis cerrojos, como lo son aquestos? (pp. 95-96).

Sin embargo, el señor Nemesio, el sacristán, se niega decididamente a abrir la alacena, donde además de lo que habitualmente se guarda en ella (un copón viejo, el cáliz de uso diario en la misa y la botella con el vino de celebrar, para tenerlo lejos del alcance de los monaguillos), hay algo bien distinto del pretendido talismán que imaginara don Quijote, como se explica hacia el final del capítulo:

15. Por ejemplo, en I, 49 don Quijote inventa una historia caballeresca tipo, la del Caballero del Lago; recordemos además la historia de la princesa Micomicona fingida por Dorotea para sacar a don Quijote de Sierra Morena, o la de la dueña Dolorida en el palacio ducal. 


\begin{abstract}
Abriéronla enhoramala para don Quijote y para el señor Nemesio, porque, aunque hallaron como había manifestado este, un añosísimo cáliz y otro usado a diario, encontraron otrosí junto a ellos algo que el sacristán habíales celado: un trozo de pan con tortilla y unas viejas alpargatas, todo ello envuelto en unos arremendados calzones, cosas de las que había ido proveído porque, al dar remate a los funerales, pensaba irse a regar unos bróquiles a su huerta (p. 97).
\end{abstract}

Además de este humorístico episodio original del escritor navarro, debemos mencionar otra aventura que evoca las antiguas caballerescas: cuando el cura don Xavier baila durante la sobremesa de la cena a manera de gigante de la comparsa de Tafalla, don Quijote reacciona — todo lo que tenga que ver con gigantes le trastorna el juicio y lo transporta de inmediato al terreno de lo caballeresco - arremetiendo contra él (es algo similar a lo que sucede en el episodio del retablo de maese Pedro, cuando don Quijote carga contra el teatrillo donde se representa la historia de Melisendra, desbaratando muchas de las figurillas). En la novela de Larráyoz Zarranz, don Quijote cree que un cazo de sopa que tiene al alcance de la mano es un venablo, y tal es el arma con la que pretende atacar al gigante-don Xavier.

\title{
3.4. Dulcinea y el amor
}

El amor es el motor principal del actuar del caballero andante, la fuerza que le da vida y ser («Ella pelea en mí y vence en mí, y yo vivo y respiro en ella, y tengo vida y ser», leemos en Quijote, II, 30), y el servicio amoroso a «su sin par Dulcinea», la alta señora de sus altos pensamientos, queda evocada en el texto de Larráyoz Zarranz en la frase «juramos fidelidad a una única y sola dama» que pronuncia don Quijote. En cualquier caso, la presencia de Dulcinea, aparte algunas menciones sueltas de este tipo, no adquiere en esta obra una función estructural, ni siquiera una importancia destacada.

Añadiré para cerrar este apartado que la intertextualidad de la obra, además de con el Quijote, se produce con la novela histórica Amaya o Los vascos en el siglo VIII (1879), de Francisco Navarro Villoslada, de la que hay claros ecos: así, la alusión a la célebre expresión Domuit vascones con la que comenzaban las crónicas de los reinados de todos los monarcas godos, la legendaria elección de Jimeno García como primer rey de Pamplona, o el comienzo del capítulo II, con un comentario del narrador que recuerda mucho el estilo del escritor vianés (aprendido, a su vez, en Cervantes y el Quijote ${ }^{16}$, inicio y origen último de toda la novela moderna occidental):

16. Para la influencia de Cervantes en Navarro Villoslada, véase Carlos Mata Induráin, Francisco Navarro Villoslada (1818-1895) y sus novelas históricas, Pamplona, Gobierno de Navarra (Dpto. de Educación, Cultura, Deporte y Juventud-Institución «Príncipe de Viana»), 1995; y Carlos Mata Induráin, «Cervantes y Navarro Villoslada. Reminiscencias quijotescas en el Pedro Ramírez», Pregón 
Mejor será, paciente lector, dejar de lado todas estas disquisiciones de las escuelas, para seguir más de cerca al Caballero de la Triste Figura en sus primeros pasos por el reino de Navarra, que por habernos detenido en ellas más de la cuenta, hemos dado lugar a que háyannos dejado rezagados (p. 24).

\section{LenguAJE Y ESTILO}

Examinaré en este apartado aquellos aspectos más destacados como son: el uso de navarrismos y vulgarismos; de refranes, frases hechas y juramentos; de arcaísmos y anacronismos; de creaciones léxicas jocosas; y, por último, los elementos que ponen de manifiesto la erudición del autor. Veamos:

\subsection{Navarrismos y vulgarismos}

Desde el punto de vista lingüístico, uno de los rasgos más destacados de la novela es la abundancia de navarrismos, es decir, palabras y expresiones propias (aunque no siempre exclusivas) del habla de Navarra ${ }^{17}$, y en particular, en esta novela, de la zona de Tierra Estella (aparecen concentrados, sobre todo, en los capítulos dedicados al encuentro de don Quijote y Sancho con el carbonero Saturnino, que es de lo más logrado y gracioso de la novela, junto con los diálogos, muy humorísticos, que entablan con los curas y el mocete). Así, tenemos los siguientes: acullo («aguijón de hierro»), auxia («aparta, fuera de aquí»), bea («mosca de macho»), boche («pollino»), casar a Larraona («casarse para irse a vivir a Larraona»), charrancha («palo que se coloca en los carros para acarrear mieses»), fuesa («cajón con agujeros para colocar velas en la iglesia»), goñe (lo mismo que coñe, eufemismo), jiniebros («enebros»), jolín («gresca, jolgorio, diversión bulliciosa»), entavía («todavía»), vulcar («caer derribado»), langarriar («lloviznar»), mucho judíos («muy judíos, muy ladinos»), mucho recia («muy recia»), muete («muchacho, mozo»), zartakos («bofetadas, sopapos»), ni órdigas («ni nada de nada»), ola$d a$ («pan que se ofrenda por un difunto»), oncena («junta concejil»), ondarras («heces, residuos, restos»), ipautri! («ipara otro!»), pértica («una de las partes de la aguijada»), redodillas (por de rodillas), remilgosas («remilgadas»), roya («roja»), torcidas («pajuelas de azufre»), etc. También encontramos algunos casos de empleo del diminutivo en -ico propio del habla de Navarra (y también de otras regiones de España e Hispanoamérica): rapacicos, moceticos, fuentecica, don Quijotico.

Siglo XXI, n. ${ }^{\circ}$ 10, Navidad de 1997, pp. 63-66 (reeditado en Doce estudios sobre Navarro Villoslada. Semblanza y obras literarias, Viana, Ayuntamiento de Viana, 2002, pp. 199-207).

17. Véase para este aspecto José María Iribarren, Vocabulario navarro, 3. a ed., Pamplona, Diario de Navarra, 1997; y Carmen Saralegui, Navarrismos en el Diccionario de la Real Academia Española, Pamplona, Gobierno de Navarra (Departamento de Educación y Cultura), 2001. 
Para caracterizar a los personajes de baja extracción social, entran con frecuencia en sus diálogos expresiones coloquiales y vulgarismos varios (vacilación en la pronunciación de las vocales átonas, reducción de los grupos consonánticos cultos...): ecetra, linun crucis (pronunciación vulgar de etcétera y lignum crucis), tiricia, nálisis, escisión (vulgarismos por ictericia, análisis y excepción), agüelo, acetará, resino (en vez de aceptará y resigno, con reducción vulgar del grupo consonántico culto), voquiblos, lición, alcaduz (pronunciación vulgar de arcaduz), cerimonias, esceción, deputados, mochacho, pue (por puede), etc. A esto habría que sumar los numerosos casos de laísmo (usuales también en el discurso del narrador), los participios del tipo forrau, ganau (forrado, ganado), formas verbales como habíai (por había) o la confusión de deber + infinitivo, obligación, y deber de + infinitivo, probabilidad (en la novela leemos, por ejemplo, un debió dejarlos que tendría que ser debió de dejarlos).

Mención aparte requieren las prevaricaciones idiomáticas de Sancho Panza, gran «prevaricador del buen lenguaje» en el Quijote, donde encontramos ejemplos graciosamente inolvidables: por ejemplo, feo Blas por Fierabrás, sobajada por soberana, flemáticos por cismáticos, cananeas por hacaneas, tortolicas por trogloditas, estropajos por antropófagos o presonajes por personajes. En la novela de Larráyoz Zarranz tenemos también algunos ejemplos: Sancho no entiende la palabra esquizofrénico y al tratar de pronunciarla dice esquilo... diablos; tampoco comprende los topónimos vascuences correspondientes a los pueblos de la zona, Larraona, Aranarache, Zudaire y Baríndano, y los transforma humorísticamente en Larriuna, Alanarranches, Zulaire y Barincuernos. Además, Sancho tampoco comprende bien los tecnicismos profesionales de la jerga médica:

—Eso mesmo me creo yo [...], que oí a un cierto médico nombrar con tan extrañas palabras un simple dolor de barriga que tiénelo cualquier rapaz, que creí cierto ser mal de muerte. Y en otra sazón, cuando un cirujano, que al azar pasó por ante mi casa, vio a mi Teresa con un romadizo de a maravedí, díjoselo el mesmo mal con tal traza de voquiblos, que creime presto quedar viudo (pp. 47-48).

Cita donde voquiblos parece cruce entre voquibles (forma documentada en el Quijote) y vocablos, y es en cualquier caso deformación burlesca de la palabra culta. 


\subsection{Refranes, frases hechas y juramentos}

De los muchos pasajes del Quijote en que se introducen refranes ${ }^{18}$ (sobre todo en boca de Sancho, pero también en la de don Quijote y otros personajes; la afición a los refranes y frases proverbiales no era propia en exclusividad del pueblo bajo: gustaban igualmente de ellos las clases cultas en el Renacimiento), y de los pasajes en que se reflexiona sobre su empleo, podemos destacar este de I, 21:

-Paréceme, Sancho, que no hay refrán que no sea verdadero, porque todos son sentencias sacadas de la mesma experiencia, madre de las ciencias todas.

O este otro de I, 25 en que Sancho acumula una larga serie de refranes:

-Ni yo lo digo ni lo pienso [...]; allá se lo hayan, con su pan se lo coman; si fueron amancebados o no, a Dios habrán dado la cuenta; de mis viñas vengo, no sé nada, no soy amigo de saber vidas ajenas, que el que compra y miente, en su bolsa lo siente. Cuanto más, que desnudo nací, desnudo me hallo: ni pierdo ni gano; mas que lo fuesen, ¿qué me va a mí? Y muchos piensan que hay tocinos, y no hay estacas. Mas ¿quién puede poner puertas al campo? Cuanto más, que de Dios dijeron.

—iVálame Dios — dijo don Quijote—, y qué de necedades vas, Sancho, ensartando! ¿Qué va de lo que tratamos a los refranes que enhilas? Por tu vida, Sancho, que calles, y de aquí adelante, entremétete en espolear a tu asno, y deja de hacello en lo que no te importa.

En II, 10 leemos:

-Yo iré y volveré presto - dijo Sancho-; y ensanche vuestra merced, señor mío, ese corazoncillo, que le debe de tener agora no mayor que una avellana, y que donde hay tocinos, no hay estacas; y también se dice: donde no piensa, salta la liebre [...]

- Por cierto, Sancho — dijo don Quijote-, que siempre traes tus refranes tan a pelo de lo que tratamos cuando me dé Dios mejor ventura en lo que deseamos.

En II, 30, cuando don Quijote lo manda en embajada a presentarse ante Dulcinea, Sancho encaja dos refranes nada más decir que no los empleará:

-Y mira, Sancho, cómo hablas, y ten cuenta de no encajar algún refrán de los tuyos en tu embajada.

18. Para los refranes del Quijote remito, entre la abundante bibliografía existente, al apéndice «Los refranes del Quijote», en la edición de Vicente Gaos, Madrid, Gredos, 1987, vol. III, pp. 324-328, donde ofrece un listado completo; y también a los trabajos de María Cecilia Colombí, Los refranes en el «Quijote»: texto y contexto, Potomac (Maryland), Scripta Humanistica, 1989, y de Jesús María Ruiz Villamor y Juan Manuel Sánchez Miguel, Refranero popular manchego y los refranes del "Quijote», 2. ${ }^{a}$ ed., Ciudad Real, Diputación de Ciudad Real (Área de Cultura), 1999. 
— ¡Hallado os le habéis al encajador! —respondió Sancho—. ¡A mí con eso! ¡Sí, que no es esta la primera vez que he llevado embajadas a altas y crecidas señoras en esta vida!

- Si no fue la que llevaste a la señora Dulcinea — replicó don Quijote-, yo no sé que hayas llevado otra, a lo menos en mi poder.

-Así es verdad — respondió Sancho-; pero al buen pagador no le duelen prendas, y en casa llena presto se guisa la cena, quiero decir que a mí no hay que decirme ni advertirme de nada, que para todo tengo y de todo se me alcanza un poco.

Recordaré, en fin, este otro pasaje de II, 43, cuando don Quijote da consejos a Sancho Panza antes de que acuda al gobierno de la ínsula Barataria:

- También, Sancho, no has de mezclar en tus pláticas la muchedumbre de refranes que sueles; que puesto que los refranes son sentencias breves, muchas veces los traes tan por los cabellos, que más parecen disparates que sentencias.

—Eso Dios lo puede remediar — respondió Sancho—, porque sé más refranes que un libro, y viénenseme tantos juntos a la boca cuando hablo, que riñen por salir unos con otros; pero la lengua va arrojando los primeros que encuentra, aunque no vengan a pelo. Mas yo tendré cuenta de aquí adelante de decir los que convengan a la gravedad de mi cargo, que en casa llena presto se guisa la cena, y quien destaja no baraja, y a buen salvo está el que repica, y el dar y el tener seso ha menester.

— ¡Eso sí, Sancho! — dijo don Quijote-. ¡Encaja, ensarta, enhila refranes, que nadie te va a la mano! ¡Castígame mi madre, y yo trómpogelas! Estoyte diciendo que escuses refranes, y en un instante has echado aquí una letanía dellos que así cuadran con lo que vamos tratando como por los cerros de Úbeda. Mira, Sancho, no te digo yo que parece mal un refrán traído a propósito; pero cargar y ensartar refranes a troche moche hace la plática desmayada y baja.

Pues bien, a continuación ofrezco un listado con algunos de los refranes incluidos en Don Quijote en las Améscoas:

A buen amigo le prueba el peligro.

iA mi padre llamaron hogaza y yo me muero de hambre!

A mujer barbuda, de lejos se la saluda.

A quien madruga, Dios le ayuda, dijo Antón cuando se halló un doblón.

Al buen callar llaman Sancho.

Al que duerme a la hora de segar, se le pasa la de almorzar.

Al que no está hecho a bragas, las costuras le hacen llagas.

Aunque callo, piedras apaño.

Cada cuba huele al vino que tiene.

Cada uno obra como quien es.

De ruin paño, nunca buen sayo.

El abad, donde canta, de ahi yanta.

El amor y la fe en las obras se ve.

El muerto al hoyo y el vivo al bollo. 
En yendo delante, presto o tarde, llégase a Carrizosa y a los Infantes.

Gato escaldado del agua fría huye.

Los duelos con pan son menos.

Madrastra, el nombre le basta.

Más vale vergüenza en cara que mancilla en corazón.

Muera Marta, pero muera harta.

Nadie tienda más la pierna de cuanto fuere larga la sábana.

$\mathrm{Ni}$ en burlas ni en veras, con el grande partas peras.

No se deben echar las margaritas a los puercos.

No se hizo la miel para la boca del asno.

Ojos que no ven, corazón que no siente.

Quien mira al cielo, tropieza y quebrarse ha las narices.

Ruego de rey, mandato es.

San Miguel de las uvas, que viene tarde y poco dura.

Si dieres el pie al villano, presto tomarte ha la mano.

Si quieres aprender a orar, teme váyante a apalear.

Si quieres casar, casa con tu igual.

Si viniere el gabacho, ni mujer, ni consejo, ni mula, ni macho.

Sin nada no hay nada.

Sin tormenta no hay bonanza, y sin cuaresma no hay Pascua.

Tiempo y hora no se atan con soga.

Unos levantan la caza y otros la matan.

Vase el tiempo como el viento.

Vientre ayuno, no oye a ninguno.

A los refranes propiamente dichos debemos añadir algunas frases hechas: a la fuerza ahorcan, como el gallo morón [sic, por de Morón], sin plumas y cacareando, como piojos en costura, con la Iglesia tornamos a topar, corazones come Dios, de menos te hizo Dios, diciendo y haciendo, no se le cocía el pan, nos comamos ambos los codos tras ellas, que no me dejará mentir, se me ha venido a los dientes... Y juramentos o maldiciones exclamativas como: ¡Mala landre la dé el diablo...! o ;Válame el cuerpo de San Nicomedes!

\subsection{Arcaísmos y anacronismos}

Abundan también los arcaísmos (a veces simples cultismos gráficos, esto es, conservación de los grupos consonánticos cultos) que tratan de reproducir la fabla medievalizante de don Quijote: acontescía, añuencia, asaz cantada, atales («tales»), corrido («avergonzado») y corrimiento («vergüenza»), do (por donde), estorias, fazañas, fechos, fee (por fe), felice (-e paragógica), fermosos, fincara («quedara»), licción, lueñe («lejano»), magüer (sic, por maguer, «aunque»), mal de su grado, nívea albura, plañirte, priesa, quienquier («cualquier»), quistión, rescibir, sacra veste, suso («arriba»), truje (en vez de traje), voacé («vuestra merced»). También debemos añadir el empleo de alguna contracción (deste por de este, dellos por de ellos); construcciones de artículo + posesivo + sustantivo (la su boca, el su poderío, un su compañe- 
ro...), el empleo de la conjunción copulativa $e$ (en vez de $y$ ) o formas verbales perifrásticas como mostrarle he.

En sentido contrario, otro rasgo de estilo es la introducción por parte del narrador de algunas alusiones a la realidad contemporánea (ya indiqué que la acción de la novela parece situarse vagamente a finales del siglo XIX o principios del XX): la mención de los ejércitos realistas (enfrentados a los carlistas), el apelativo despectivo liberaloides aplicado a los enemigos políticos; toda la invectiva contra Johannes de Olio, que parece ser respuesta a cierta lección magistral realmente pronunciada en Pamplona por un profesor llamado Juan Ollo; o la mención de esa «dolencia nueva que han dado en llamar "psicoanálisis"» o la alusión a «la farsa de aqueste siglo».

\subsection{Juegos de palabras}

Abundan en la novela los juegos de palabras, especialmente los basados en las paronomasias y las dilogías. Por ejemplo:

— el sintagma «dueñas» de sí, donde se juega con la frase hecha ser alguien dueño de sí mismo y la condición de dueñas («sirvientas de edad avanzada») de las mujeres;

- el chiste escatológico por disociación de la palabra peda-gogía;

— el juego de palabras con Altísimo y altísimo, «Dios» en el primer caso, «varón muy alto» en el segundo;

- el juego con más mancha que la del nombre de su patria/lustrar esa Mancha, con la dilogía de lustrar la mancha «limpiarla, lavarla» y lustrar la Mancha «ilustrar, hacer famosa la región natal de don Quijote»;

— el juego pucheros/cazolones, con dilogía de pucheros «gestos que preceden al llanto» y «recipientes de barro»;

- la paronomasia mesa/misa, fácil juego de palabras repetido varias veces a lo largo de la novela, y también infulas/ínsulas;

- la disociación departir/de partir;

- el chiste basado en la expresión hacer buenas migas «trabar una relación amistosa, congeniar», pero con alusión festiva al guiso hecho precisamente con pan desmigado;

— la dilogía de corteza, «lo opuesto a largueza» y «corteza de pan», en la expresión con largueza y corteza;

- el fácil juego de palabras basado en la paronomasia en los sintagmas caballero descabellado, sin par pareja, tan encantado como encantador castillo;

— el juego con el apellido Fortún, puesto en relación con la palabra fortuna;

- la expresión zeugmática gracia... la que hacía a su amo, con dilogía en la palabra gracia, pues en la primera parte de la frase significa «salero, habilidad» mientras que en la segunda vale «contento, agrado». 


\subsection{Creaciones léxicas jocosas}

Rastreamos la presencia de varias creaciones léxicas jocosas como alcurnios («personajes de alta alcurnia», en un par de ocasiones), aleluyar («alegrarse»), condeses (plural humorístico de conde), contumeliar y contumeliado («ofender» $\mathrm{y}$ «ofendido»). Carácter humorístico revisten asimismo los adjetivos en -il: pecho escuderil, coro dueñil, gentes escuderiles. Recordemos que Cervantes gusta mucho de estos adjetivos en -il y, así, en el Quijote encontramos venteril, escuderil, condesil, bosqueril, jumentiles, cencerril..., creaciones no exentas de cierto tono jocoso, igual que sucede con los latinajos. En efecto, el latín aparece en la novela de Larráyoz Zarranz en citas serias (Domuit vascones, Nunc dimittis!, Parce mihi, Domine, Taedat animam meam vitae meae, Manus tuae fecerunt me...), pero también con fines humorísticos, como en la pronunciación vulgar linun crucis, el latinajo ne me la recorderis («no me la recuerdes») o el chiste que hace Sancho al oír otra expresión latina del oficio de difuntos: «Pelle et carnibus vestisi me? ¡A abadejo me huelen aquestos latinajos!» (con error, además, al modificar el vestiti de la frase original en vestisi), o la mención de un quesus boli (chiste basado en el parecido fonético con la expresión jurídica casus belli). Graciosos son también algunos de los juramentos que pronuncian los personajes (del tipo «¡Válame el cuerpo de San Nicomedes!») o la mención de algún santo como San Acisclo que, aunque responde a un santo real, bien pudiera ser, en el contexto en que se inserta, puramente burlesca.

\subsection{Elementos de erudición}

Martín Larráyoz Zarranz es un escritor con una muy buena base de conocimientos humanistas (no olvidemos su doble condición de sacerdote y de historiador), lo que se trasluce en la mención continua de:

— personajes y episodios de la Biblia o la tradición religiosa judeocatólica: Longinos, el valle de Josefá (pronunciación vulgar de un personaje, aludiendo al valle de Josafat), el profeta Eliseo, el rey David, la bíblica mujer fuerte, los hermanos Macabeos, San Rafael, etc.;

— personajes y episodios de la Mitología, la Antigüedad greco-latina y la Historia: los ríos Janto y Termodonte, las luchas de Hércules con el Centauro, la diosa Fortuna, Indíbil y Mandonio, Nabucodonosor, Héctor, Áyax, Diomedes, Patroclo, Príamo, Hécuba, Deífobo, Aquiles, Filóstratos, las sibilas de Cumas y de Tíbur, las Gracias, las Musas, el mar Hespérido, el Preste Juan de las Indias...; y

- personajes relacionados con la historia de la literatura, la leyenda, la cultura o las artes plásticas: el canciller dom Pero López de Ayala, Homero, Santo Tomás de Aquino, Porfirio, el Greco, fray Luis de León, Tommaso da Celano, el Tostado, Garcilaso de la Vega, Alejandro de Adrián, Galeno o Teodosio de Goñi, entre otros. 


\section{VALORACIÓN FINAL}

Don Quijote en las Améscoas no es, ciertamente, una obra de una excepcional calidad literaria, pero sí que ofrece un indudable interés por la estrecha relación que establece entre la novela y el personaje cervantinos, el Quijote y don Quijote, con Navarra y los navarros. Ya he aludido a la abundante intertextualidad con el modelo del XVII, que demuestra perfectamente que Martín Larráyoz fue un buen lector de Cervantes y que había asimilado con aprovechamiento su fecunda enseñanza. Y, además, es una obra a trechos muy graciosa y divertida, en especial en aquellos pasajes humorísticos en los que el autor da entrada a distintos personajes navarros con los que topan don Quijote y Sancho (el carbonero Saturnino, los curas, algún que otro mocete...), caracterizados todos ellos por su peculiar forma navarra de hablar. Esos pasajes llenos de humor y de navarrismos -o de navarrismos introducidos con fines humorísticos- constituyen, de hecho, las mejores páginas de la novela. Por lo demás, como señalaba al principio, esta novela de Larráyoz Zarranz — que merecería contar con una edición preparada con criterios científicos y convenientemente anotada - viene a sumarse a la copiosísima serie de recreaciones que, en todos los géneros literarios y en las más variadas artes, ha generado la inmortal creación cervantina a lo largo de los siglos, desde su mismo momento de aparición, recreaciones que, sin duda alguna, se seguirán produciendo en el futuro dada la enorme potencialidad del Quijote y la condición de mito universal de su protagonista.

\section{BIBLIOGRAFÍA}

Alvar, Carlos (dir.), Alvar Ezquerra, Alfredo y Sevilla Arroyo, Florencio (coords.), Gran enciclopedia cervantina, Madrid, Castalia-Centro de Estudios Cervantinos, 20052010, 9 vols.

Avalle-Arce, Juan Bautista de, Enciclopedia cervantina, 2.a ed., Guanajuato (México), Universidad de Guanajuato, 1997.

«Caja de Ahorros de Navarra (CAN)», en Gran Enciclopedia Navarra, Pamplona, Caja de Ahorros de Navarra, 1990, vol. III, pp. 47-52.

Cervantes, Miguel de, Don Quijote de la Mancha, ed. del Instituto Cervantes dirigida por Francisco Rico, Barcelona, Crítica, 1998, 2 vols.

Cervantes, Miguel de, Don Quijote de la Mancha, ed. Vicente Gaos, Madrid, Gredos, 1987, 3 vols.

Colombí, María Cecilia, Los refranes en el "Quijote»: texto y contexto, Potomac (Maryland), Scripta Humanistica, 1989.

Iribarren, José María, Vocabulario navarro, 3. ${ }^{a}$ ed., Pamplona, Diario de Navarra, 1997.

LARRÁYOZ ZARRANZ, Javier, «El Quijote de Navarra. Vida y aventuras del brigadier de los ejércitos carlistas don Mariano Larumbe», Príncipe de Viana, n. ${ }^{\text {os }} 148-149$, 1977, pp. 605-627 y $150-151,1978$, pp. 203-280. 
Larráyoz Zarranz, Martín, Don Quijote en las Améscoas, revisión y prólogo de Víctor Manuel Arbeloa, Pamplona, Medialuna Ediciones, 1993.

LARRAZ, Pablo, Entre el frente y la retaguardia. La sanidad en la guerra civil: el Hospital «Alfonso Carlos», Pamplona, 1936-1939, Madrid, Actas, 2004.

LÓPEZ NAVIA, Santiago Alfonso, Inspiración y pretexto. Estudios sobre las recreaciones del «Quijote», Madrid-Frankfurt, Iberoamericana-Vervuert, 2005.

Mata InDURÁIn, Carlos, Francisco Navarro Villoslada (1818-1895) y sus novelas históricas, Pamplona, Gobierno de Navarra (Dpto. de Educación, Cultura, Deporte y Juventud-Institución «Príncipe de Viana»), 1995.

MATA INDURÁIN, Carlos, «Cervantes y Navarro Villoslada. Reminiscencias quijotescas en el Pedro Ramírez», Pregón Siglo XXI, n. ${ }^{\circ}$ 10, Navidad de 1997, pp. 63-66. Reeditado en Carlos Mata Induráin, Doce estudios sobre Navarro Villoslada. Semblanza y obras literarias, Viana, Ayuntamiento de Viana, 2002, pp. 199-207.

Navallas Rebolé, Arturo (dir.), Navarra y la Caja en 75 años: 1921-1996, Pamplona, Caja de Ahorros de Navarra, 1996.

Ruiz Villamor, Jesús María y SÁnchez Miguel, Juan Manuel, Refranero popular manchego y los refranes del «Quijote», 2. ${ }^{\mathrm{a}}$ ed., Ciudad Real, Diputación de Ciudad Real (Área de Cultura), 1999.

SARAlegui, Carmen, Navarrismos en el Diccionario de la Real Academia Española, Pamplona, Gobierno de Navarra (Departamento de Educación y Cultura), 2001.

Recibido: 5 de mayo de 2011

Aceptado: 18 de octubre de 2011 


\title{
Resumen
}

Este artículo analiza una recreación narrativa del Quijote de mediados del siglo XX, Don Quijote en las Améscoas, de Martín Larráyoz Zarranz, quien traslada a don Quijote y Sancho Panza a tierras navarras. La novela, publicada en 1954 en una revista diocesana pamplonesa y luego en forma de libro en 1993, constituye un eslabón más en la larga y fecunda cadena de recreaciones del inmortal personaje cervantino y sus aventuras, una prueba más de su enorme vigencia como mito universal.

Palabras clave: Cervantes. Quijote. Recreaciones cervantinas. Martín Larráyoz Zarranz. Améscoas.

Title: A Narrative Recreation of Don Quixote at Mid-Twentieth Century: Don Quijote en las Améscoas, by Martín Larráyoz Zarranz

\begin{abstract}
This article examines a narrative recreation of Don Quixote at mid-twentieth century, Don Quijote en las Améscoas, by Martín Larráyoz Zarranz, who takes Don Quixote and Sancho Panza to Navarre. The novel, published in 1954 at a diocesan magazine of Pamplona and then in book form in 1993, is another link in the long and fruitful chain of recreations of Cervantes' immortal character and his adventures, a proof of its validity as an universal myth.
\end{abstract}

Key words: Cervantes. Don Quixote. Cervantes Recreations. Martín Larráyoz Zarranz. Améscoas. 